\title{
Indonesian Social Health Insurance Sample Data are Now Available and Accessible for Research
}

\author{
Anis Fuad ${ }^{1}$ (D) \\ Published online: 4 July 2019 \\ (c) The Author(s) 2019
}

\section{Dear Editor,}

I would like to congratulate the authors of the article titled "National health insurance databases in Indonesia, Vietnam and the Philippines", which was recently published in PharmacoEconomics Open [1]. This article has correctly underlined the importance of social health insurance administrative data to support these Southeast Asian countries toward the achievement of universal health coverage (UHC) [1]. Experiences in other countries have shown that administrative data could significantly contribute to knowledge development, public health decision making, and various other purposes if the data were available and easily accessible [2].

The authors mentioned that accessibility to administrative data was among the main challenges, especially for Indonesian researchers. After submitting a data request, researchers could wait up to 6 months to get a response, along with additional waiting time queuing for access to data, and onsiteonly analysis, until finally generating the data in an aggregated format [1]. The Indonesian Social Health Security Agency (BPJS Kesehatan) maintained such procedures to protect data privacy and confidentiality, as well as to facilitate researchers for direct consultation with data custodians due to the complexity and huge volume of data.

Fortunately, this situation changed just a few weeks before the article appeared online. In February 2019, BPJS Kesehatan launched the 2015-2016 social health insurance sample data (SHISD), a nationally representative administrative dataset that was randomly sampled from strata of BPJS Kesehatan members in 2015-2016.

The sampling frame of the SHISD was a list of $73,441,160$ families who were enrolled as members at

Anis Fuad

anisfuad@ugm.ac.id

1 Department of Biostatistics, Epidemiology and Population Health, Faculty of Medicine, Public Health and Nursing, Universitas Gadjah Mada, Yogyakarta, Indonesia
22,024 'gatekeepers', including primary health care sites (Puskesmas), family physicians, and clinics. 'Gatekeepers' subgrouped these families into three categories: (1) families who have never utilized any health care services; (2) families who have ever visited gatekeepers; and (3) families who have visited primary and referral care. Within each category, a minimum of 10 families were randomly sampled. If selected, all individuals in the family were included in the dataset. Finally, from the 66,072 strata, a sample of 586,969 families was selected, constituting a total of 1,697,452 individuals [3].

The SHISD consists of four relational tables, namely membership, capitation-based primary care services, noncapitation-based primary care services, and referral care services. The membership table contains the necessary variables, including an identifier of individuals and families, details of demographic and membership characteristics, and a weight variable of each record. In this dataset, the weight variable represents a certain number of BPJS Kesehatan members. The remaining tables consist of details of visits, health facility characteristics, and individual identifiers. The SHISD has been distributed to universities, research institutions, and other relevant stakeholders in Indonesia. This anonymized dataset, as well as the book code, is available from BPJS Kesehatan upon reasonable request [3].

I have tried to analyze the table of referral care services to generate the unweighted temporal distribution of hospitalized dengue hemorrhagic fever (DHF) cases and the association between length of stay (LOS) and the reimbursement amount for hospitalized DHF cases (Figs. 1 and 2).

From approximately 911,000 referral visits, including outpatient and inpatient care, 6104 records were inpatient cases with a primary diagnosis of DHF (International Classification of Diseases, Tenth Revision [ICD-10] code A91). Samples of inpatient cases in the year 2016 were more than double the number in the year 2015 (4130 vs. 1974 records). The surge of cases in 2016 was slightly higher than the official surveillance report. The Indonesian 


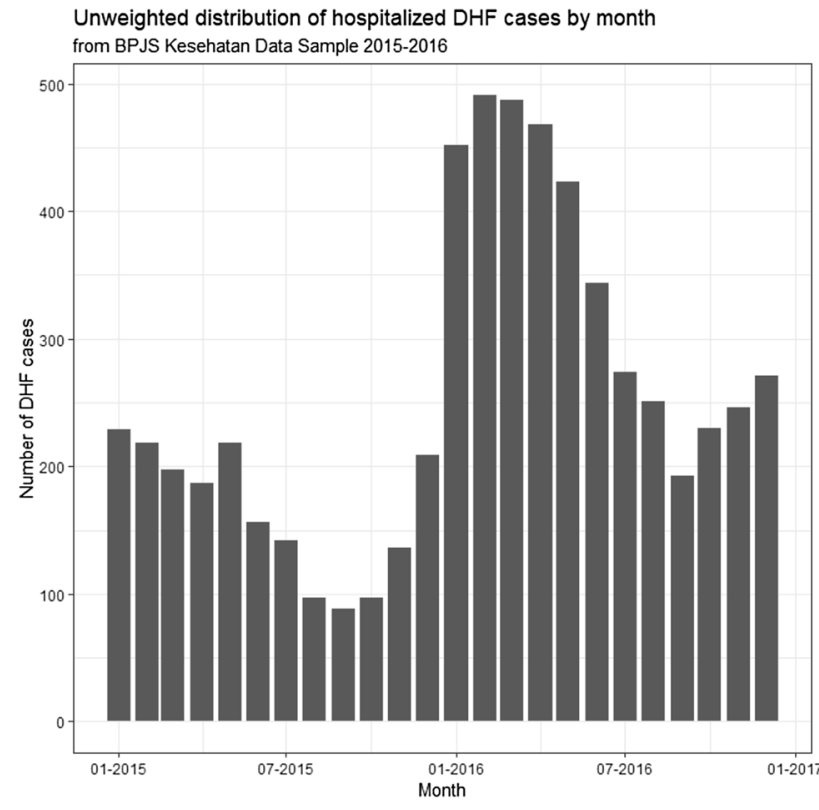

Fig. 1 Distribution of hospitalized DHF cases, by month (source: BPJS Kesehatan Data Sample 2015-2016). DHF dengue hemorrhagic fever

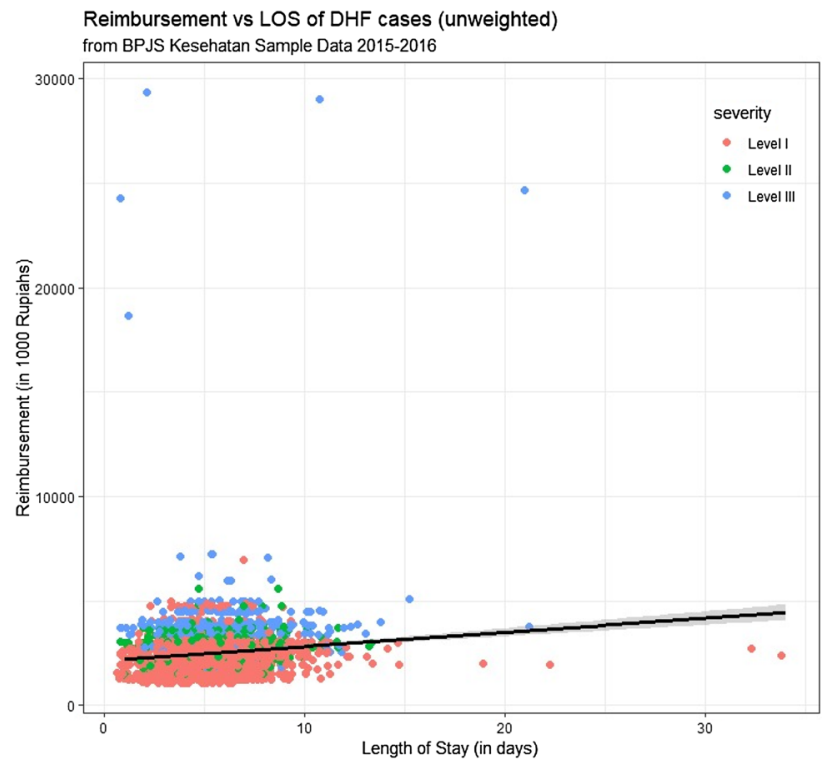

Fig. 2 Unweighted reimbursement vs. LOS of hospitalized DHF cases (source: BPJS Kesehatan Data Sample 2015-2016). DHF dengue hemorrhagic fever, LOS length of stay

Ministry of Health reported that the incidence rate of DHF in 2016 was 78.85 per 100 thousand population, or approximately 1.5 -fold higher than in 2015 (50.75 per 100 thousand population). Indeed, the incidence rate in 2016 was highest in 2008-2017. A national surveillance report also mentioned that the DHF incidence rate in 2017 was lowest within that same decade [4].

Therefore, it is highly recommended that BPJS Kesehatan continuously generate the SHISD in the following years to produce continuous epidemiological knowledge and information to support the surveillance program, which will be useful for measuring the magnitude and burden of various diseases, especially those that are underreported by limited surveillance programs. As a seasonal disease, SHISD showed that DHF cases increased in the rainy season (October 2015-April 2016) and reached a peak in February 2016.

Figure 2 illustrates the association between LOS and the reimbursement amount received by the hospital for each hospitalized DHF case. The mean reimbursement cost was Indonesian rupiah (IDR) 2,489,592 (range IDR 1,047,100-29,356,200), while the mean LOS was 5 days (range 1-34). The majority of inpatient DHF cases were within the low severity level (Level I).

The $R$-square of the model was 0.01656 , meaning that only $1.6 \%$ of reimbursement variance could be explained by LOS. This model predicted that for every 1 additional day during the stay, reimbursement will only rise IDR 67,849 . To improve the model, researchers should pay attention to the outlier points, for example LOS and reimbursement. Detecting, scrutinizing, and confirming outliers are essential strategies while interpreting administrative data due to data quality reasons. Knowledge regarding the Indonesian health system setting, such as the rules of the Indonesian prospective payment system, health facility characteristics, referral system, and details of specific clinical cases will help researchers to better interpret the results.

This letter is one of the first articles to discuss SHISD data in an international journal. I am hopeful that more publications exploring SHISD will soon be published. The 2015-2016 SHISD is the first and foremost step. Mutual collaboration between the scientific community, policy makers, and BPJS Kesehatan is necessary for the continued series of crucial steps directed toward improving the quality, scope, and details of Indonesian social health insurance administrative data [5].

Acknowledgements Data of DHF cases in this letter are from the Data Sampel BPJS Kesehatan 2015-2016 provided and managed by BPJS Kesehatan. The interpretations contained herein do not represent those of BPJS Kesehatan. The author would like to thank Dr Mubasysyir Hasanbasri, MA, for his constructive thoughts and advice regarding this letter.

\section{Compliance with Ethical Standards}

Conflicts of interest No conflicts of interest were disclosed.

Funding No funding was involved in supporting this work. 
Open Access This article is distributed under the terms of the Creative Commons Attribution-NonCommercial 4.0 International License (http://creativecommons.org/licenses/by-nc/4.0/), which permits any noncommercial use, distribution, and reproduction in any medium, provided you give appropriate credit to the original author(s) and the source, provide a link to the Creative Commons license, and indicate if changes were made.

\section{References}

1. Ng JYS, Ramadani RV, Hendrawan D, et al. National health insurance databases in Indonesia, Vietnam and the Philippines. Pharmacoeconomics Open. 2019. https://doi.org/10.1007/s4166 9-019-0127-2 (Epub 11 Mar 2019).
2. Hsing AW, Ioannidis JP. Nationwide population science: lessons from the Taiwan national health insurance research database. JAMA Internal Med. 2015;175(9):1527-9.

3. Ariawan I, Sartono B, Jaya C, et al. Data Sampel BPJS Kesehatan Tahun 2015-2016. Jakarta: BPJS Kesehatan; 2019.

4. Indrayani YA, Wahyudi T. Situasi penyakit demam berdarah di Indonesia tahun 2017. Infodatin; 2018. ISSN 2442-7659. http:// www.depkes.go.id/download.php?file=download/pusdatin/infod atin/InfoDatin-Situasi-Demam-Berdarah-Dengue.pdf. Accessed 10 June 2019.

5. Fuad A. Data terbuka BPJS Kesehatan: modal awal untuk ungkap misteri sains kesehatan Indonesia. The Conversation 2019. http://theconversation.com/data-terbuka-bpjs-kesehatan-modal -awal-untuk-ungkap-misteri-sains-kesehatan-indonesia-116522. Accessed 10 June 2019. 